\title{
Influence of silicate on enrichment of highly productive microalgae from a mixed culture
}

\author{
Peter R. Mooij ${ }^{1}$ Lisanne D. de Jongh ${ }^{1}$ - Mark C. M. van Loosdrecht ${ }^{1}$ • \\ Robbert Kleerebezem ${ }^{1}$
}

Received: 3 March 2015 / Revised and accepted: 21 July 2015 / Published online: 11 August 2015

(C) The Author(s) 2015. This article is published with open access at Springerlink.com

\begin{abstract}
Microalgae have the potential to supply a biobased society with essential feedstocks like sugar and lipids. Besides being productive, strains used for this purpose should grow fast, be resistant to predators, and have good harvestability properties. Diatoms, a class of siliceous algae, have these and other preferred characteristics. In this paper, we describe the enrichment of microalgae in sequencing batch reactors with and without supply of silicate. Both reactors were operated with a light-dark cycle. To maximize storage compound production, carbon fixation and nitrogen uptake were uncoupled by limiting the availability of nitrate to the dark phase. After ten cycles, a stable culture was established in both reactors. The diatom Nitzschia sp. dominated the silicate-rich reactor, and the green algae Chlamydomonas sp. dominated the silicate-depleted reactor. Over the remaining 27 cycles of the experiment, the microalgal community structure did not change, indicating a highly stable system. Although the dominant microalga was highly dependent on the presence of silicate, the performance of both microalgal enrichments was similar. Polymers of glucose were stored during the nitrogen-limited light period. On organic matter dry weight basis, the sugar content of the biomass increased during the light period from $17 \pm 4$ to $53 \pm 4 \%$ for the silicate-limited culture, and from $14 \pm 4$ to $43 \pm 4 \%\left(w w^{-1}\right)$ for the silicate excess culture. These results show that storage compound production can be achieved under various conditions, as long as a selective environment is maintained.
\end{abstract}

Peter R. Mooij

P.R.Mooij@tudelft.nl

1 Department of Biotechnology, Delft University of Technology, Julianalaan 67, 2628 BC Delft, The Netherlands
Keywords Mixed cultures · Selective environment · Green algae $\cdot$ Diatoms $\cdot$ Storage compounds

\section{Introduction}

Microalgae are efficient producers of triacylglycerides $(\mathrm{Hu}$ et al. 2008) and starch (Markou et al. 2012) and have been proposed to supply these as feedstock for food, fuels, and chemicals to a biobased economy (Wijffels and Barbosa 2010). Nowadays, microalgal research mainly focuses on pure culture applications. Production of bulk compounds, such as triacylglycerides, at an industrial scale is however troublesome in an axenic microalgal culture (Kazamia et al. 2012; Shurin et al. 2013; McBride et al. 2014). Previously, we described an ecology-based enrichment and cultivation method which allows for stable storage compound production under nonaxenic conditions (Mooij et al. 2013, 2015). The basis of this approach is uncoupling of carbon fixation in the light and nitrogen uptake in the dark by limiting the presence of an essential growth nutrient (such as nitrate) to the dark phase. Limiting the presence of nitrate to the dark period provides a competitive advantage for storage compound-producing microalgae. Microalgae that efficiently convert $\mathrm{CO}_{2}$ into storage compounds in the light phase can take up the nitrate in the dark phase for biomass production, resulting in an enrichment culture consisting of efficient storage compound-producing microalgae (Mooij et al. 2013).

Despite their overwhelming abundance in nature, diatoms are largely overlooked in microalgal biofuel and biomass production research. Diatoms possess however various characteristics which make them interesting candidates for large-scale storage compound production (Hildebrand et al. 2012). These include the capacity to accumulate large amount of lipids when exposed to silicate limitation, good resistance to 
predators, and good harvestability. The presence of diatoms in nature is to a large extent regulated by the amount of available silicate (Werner 1977). At nonlimiting silicate levels, diatoms are effective competitors for limiting nutrients and are able to effectively utilize nutrient pulses (Litchman 2007). At external silicate concentrations exceeding $2 \mathrm{mM}$, diatoms typically represent more than $70 \%$ of the phytoplankton community (Egge and Aksnes 1992). With increasing silicate to phosphorus ratios, diatom abundance increases in competition experiments between diatoms and nonsiliceous algae (Sommer 1985).

The first objective of this research was to investigate if selective enrichment of storage compound-producing diatoms can be established in an open system with a surplus of silicate in the medium. We expect the enriched microalgae community to differ in a system with and without silicate supply. The functionality of storage compound production is nonetheless expected to be present under both conditions, as it is a consequence of the uncoupling of carbon fixation and nitrogen uptake.

\section{Materials and methods}

\section{Operating conditions}

Two 1.5-L bioreactors (Applikon, The Netherlands) with a diameter of $11 \mathrm{~cm}$ and height of $17 \mathrm{~cm}$ were operated in a sequenced batch mode with the following operational parameters (Table 1). The system was operated under nonaxenic conditions. The medium composition for both reactors is

Table 1 Operational parameters

\begin{tabular}{|c|c|c|}
\hline Parameter & Unit & Value \\
\hline Light period & $\mathrm{h}$ & 16 \\
\hline Dark period & $\mathrm{h}$ & 8 \\
\hline Cycle length & $\mathrm{h}$ & 24 \\
\hline Solid retention time & $\mathrm{h}$ & 41 \\
\hline Liquid volume & $\mathrm{L}$ & 1.2 \\
\hline Temperature & ${ }^{\circ} \mathrm{C}$ & 28 \\
\hline Stirrer speed & $\mathrm{rpm}$ & 200 \\
\hline Gas flow reactor in and out & $\mathrm{NmL} \min ^{-1}$ & 50 \\
\hline Gas recycle over reactor & $\mathrm{NmL} \min ^{-1}$ & 1200 \\
\hline Gas composition & $\% \mathrm{CO}_{2}$ in air & 5 \\
\hline $\begin{array}{l}\text { Average light intensity at } \\
\text { inner reactor surface }\end{array}$ & $\mu \mathrm{mol} \mathrm{m} \mathrm{s}^{-2}$ & 650 \\
\hline Light source & - & HPS lamps \\
\hline $\mathrm{pH}$ setpoint & - & 7.5 \\
\hline Base & - & $1.0 \mathrm{M} \mathrm{NaOH}$ \\
\hline Acid & - & $0.5 \mathrm{M} \mathrm{HCl}$ \\
\hline
\end{tabular}

described in Table 2. $\mathrm{Na}_{2} \mathrm{SiO}_{3}(11.42 \mathrm{mM})$ was supplied to the silicate-excess reactor and withheld from the silicatedepleted reactor. Nitrate was supplied as the sole nitrogen source at the beginning of the dark period and was designed to be the limiting factor for algal growth. A solid retention time of $41 \mathrm{~h}$ and a cycle length of $24 \mathrm{~h}$ (Table 1) imply that every cycle $59 \%(700 \mathrm{~mL})$ of the culture was harvested and replaced with medium as in Table $2 . \mathrm{NO}_{3}-\mathrm{N}(14 \mathrm{mg})$ was therefore dosed to the system at the start of every dark period. A mixture of several freshwater samples collected from the upper layer of canals, ponds, and lakes in the vicinity of Delft, the Netherlands, was used as inoculum. Figure 1 describes the operational cycle for both reactors. A Bio Controller ADI 1030 (Applikon, The Netherlands) controlled Masterflex pumps (Cole-Parmer, USA) and mass flow controllers (Brooks Instruments, The Netherlands). The Bio Controller itself was controlled by a PC with MFCS_win software (Sartorius Stedim Systems, Germany).

\section{Analytical methods}

Samples were taken at the transition from dark to light and from light to dark. $\mathrm{NO}_{3}{ }^{-}$was determined spectrophotometrically using Dr. Lange LCK $339 \mathrm{NO}_{3}{ }^{-}$cuvette tests (Hach Lange, Germany). Silicate was determined spectrophotometrically using Dr. Lange LCW $028 \mathrm{SiO}_{2}$ cuvette tests (Hach Lange, Germany). Measurements of organic dry weight, lipids, glucose-polymers, and analysis of the microalgal community structure were done as described by Mooij et al. (2014) with the following modification. Glucose polymers were heated with $0.9 \mathrm{M} \mathrm{HCl}$ instead of $0.6 \mathrm{M} \mathrm{HCl}$. Species succession was quantified by taking pictures using a Leica
Table 2 Medium composition

\begin{tabular}{lll}
\hline Compound & Unit & Value \\
\hline $\mathrm{NaNO}_{3}{ }^{-}$ & $\mathrm{mM}$ & 1.43 \\
$\mathrm{H}_{3} \mathrm{BO}_{3}$ & $\mathrm{mM}$ & 1.66 \\
$\mathrm{CaCl}_{2} \cdot 2 \mathrm{H}_{2} \mathrm{O}$ & $\mathrm{mM}$ & 1.07 \\
$\mathrm{MgSO}_{4} \cdot 6 \mathrm{H}_{2} \mathrm{O}$ & $\mathrm{mM}$ & 0.64 \\
$\mathrm{~K}_{2} \mathrm{HPO}_{4}$ & $\mathrm{mM}$ & 0.23 \\
$\mathrm{FeCl}_{3} \cdot 6 \mathrm{H}_{2} \mathrm{O}$ & $\mathrm{mM}$ & 0.11 \\
$\mathrm{Na}_{2} \mathrm{EDTA} \cdot 2 \mathrm{H}_{2} \mathrm{O}$ & $\mathrm{mM}$ & 0.11 \\
$\mathrm{MnCl}_{2} \cdot 4 \mathrm{H}_{2} \mathrm{O}$ & $\mu \mathrm{M}$ & 7.71 \\
$\mathrm{CuSO}_{4} \cdot 5 \mathrm{H}_{2} \mathrm{O}$ & $\mu \mathrm{M}$ & 0.03 \\
$\mathrm{ZnSO}_{4} \cdot 7 \mathrm{H}_{2} \mathrm{O}$ & $\mu \mathrm{M}$ & 0.69 \\
$\mathrm{CoCl}_{2} \cdot 6 \mathrm{H}_{2} \mathrm{O}$ & $\mu \mathrm{M}$ & 0.43 \\
$\mathrm{Na}_{2} \mathrm{MoO}_{4} \cdot 2 \mathrm{H}_{2} \mathrm{O}$ & $\mu \mathrm{M}$ & 0.77 \\
$\mathrm{NaHSeO}_{3}$ & $\mu \mathrm{M}$ & 0.10 \\
$\mathrm{NaVO}_{3}$ & $\mu \mathrm{M}$ & 0.01 \\
$\mathrm{Allylthiourea}$ & $\mathrm{mg} \mathrm{L}$ & 10 \\
\hline
\end{tabular}




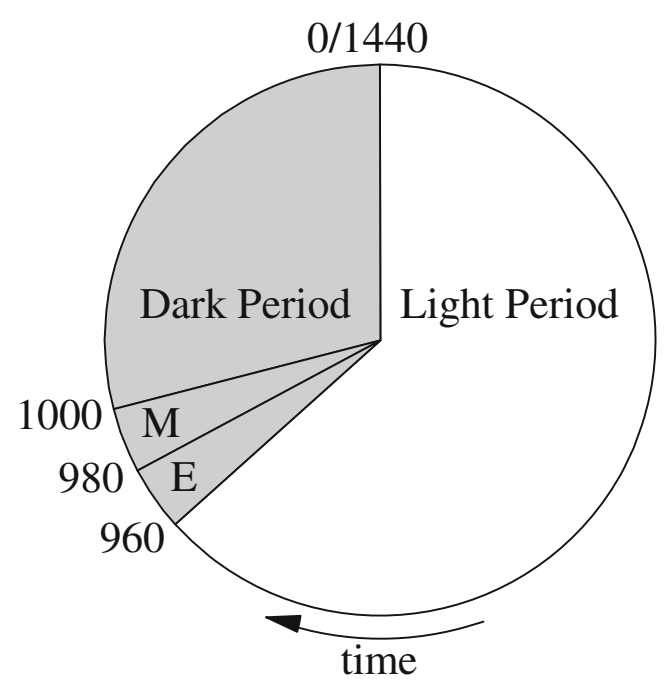

Fig. 1 Operational cycle for reactors with effluent removal $(E)$ and medium supply $(M)$ at the start of the dark period. Numbers indicate the cumulative time in minutes from the start of the cycle

DM500B light microscope (Leica Microsystems, Germany) at $\times 200$ magnification. These pictures were used to count and sort at least 300 microalgal cells per sample.

\section{Results and discussion}

\section{Microalgal community structure}

The first aim of this study was to investigate the influence of silicate presence on the selection of storage compound producing microalgae. In the absence of silicate, the operational conditions imposed resulted in the enrichment of the green alga Chlamydomonas sp. (Lobochlamys segnis, Table 3). With silicate in excess a coculture of the diatom Nitzschia sp. (accounting for $60 \%$ of the population) and the green alga Chlamydomonas was established (Fig. 2). Apparently, two microalgae could coexist under the given conditions, although only one resource, nitrate, was designed to be limited. A possible explanation for the occurrence of a coculture could be a different metabolic response to the pulse-wise addition of nitrate at the start of the dark period. Diatoms are experts in nutrient uptake and storage (Litchman 2007). Nitrate storage up to an intracellular concentration of $273 \mathrm{mM}$ has been reported (Kamp et al. 2011). This would allow diatoms to divide during periods without external nitrate, such as during the light period in this experiment. Nitrate storage in green algae is less documented, possibly limiting the period suitable for cell division to the dark period for green algae. This metabolic difference could possibly explain the observed coculture.

The dominance of Chlorella luteoviridis (Table 3) increased in both reactors during the first days of the experiment (Fig. 2). After dominating both systems for around $95 \%$ on day 3, Chlorella numbers steeply declined in the next days. A possible explanation lies in the different conditions before and after day 5 of operation. Nutrients were dosed at the start of every dark phase in both reactors. During the first days of the experiment, the limiting nutrient nitrate was not fully consumed in the dark phase (Fig. 2). The presence of nitrate in the light phase favored nutrient uptake and cell division over storage compound production, and this apparently facilitated Chlorella enrichment during this transition period. From day 5 onward, all nitrate dosed at the start of the dark phase was consumed in the dark phase; nitrate was therefore limited during the entire light phase. From this moment on, algae were not able to directly divide in the light phase. The decline of Chlorella sp. in the enrichment culture coincided with the onset of nitrogen limitation during the light period. Apparently, Chlamydomonas and Nitzschia outcompete Chlorella if carbon fixation and nitrate uptake are uncoupled. In previous work, Chlorella luteoviridis dominated the system throughout the experiment (Mooij et al. 2013). Operational differences between the previous and current work, such as the nitrogen source used and the solid retention time, could explain the disappearance of $C$. luteoviridis under the conditions applied in this experiment.

Table 3 Identity of species according to microscopic observation and PCR-DGGE analysis

\begin{tabular}{|c|c|c|c|c|}
\hline Reactor & Species determined by microscope & Species determined by PCR-DGGE & RNA gene used & Identity $(\%)$ \\
\hline \multirow[t]{4}{*}{ Silicate excess } & Chlamydomonas sp. & Lobochlamys segnis KMMCC 1045 & $18 \mathrm{~S}$ & 100 \\
\hline & Chlorella sp. & Chlorella luteoviridis CCAP 211/5B & $18 \mathrm{~S}$ & 96 \\
\hline & & Chlorella sorokiniana chloroplast & $16 \mathrm{~S}$ & 99 \\
\hline & Nitzschia sp. & Nitzschia frustulum chloroplast & $16 \mathrm{~S}$ & 100 \\
\hline \multirow[t]{4}{*}{ Silicate deplete } & Chlamydomonas sp. & Lobochlamys segnis KMMCC 1045 & $18 \mathrm{~S}$ & 99 \\
\hline & Chlorella sp. & Chlorella luteoviridis CCAP 211/5B & $18 \mathrm{~S}$ & 98 \\
\hline & & Chlorella sorokiniana chloroplast & $16 \mathrm{~S}$ & 99 \\
\hline & Nitzschia sp. & Nitzschia frustulum chloroplast & $16 \mathrm{~S}$ & 99 \\
\hline
\end{tabular}

Only the main species present are depicted 
Community Structure and

Dark Nitrate Consumption

- Silicate Deplete Reactor -
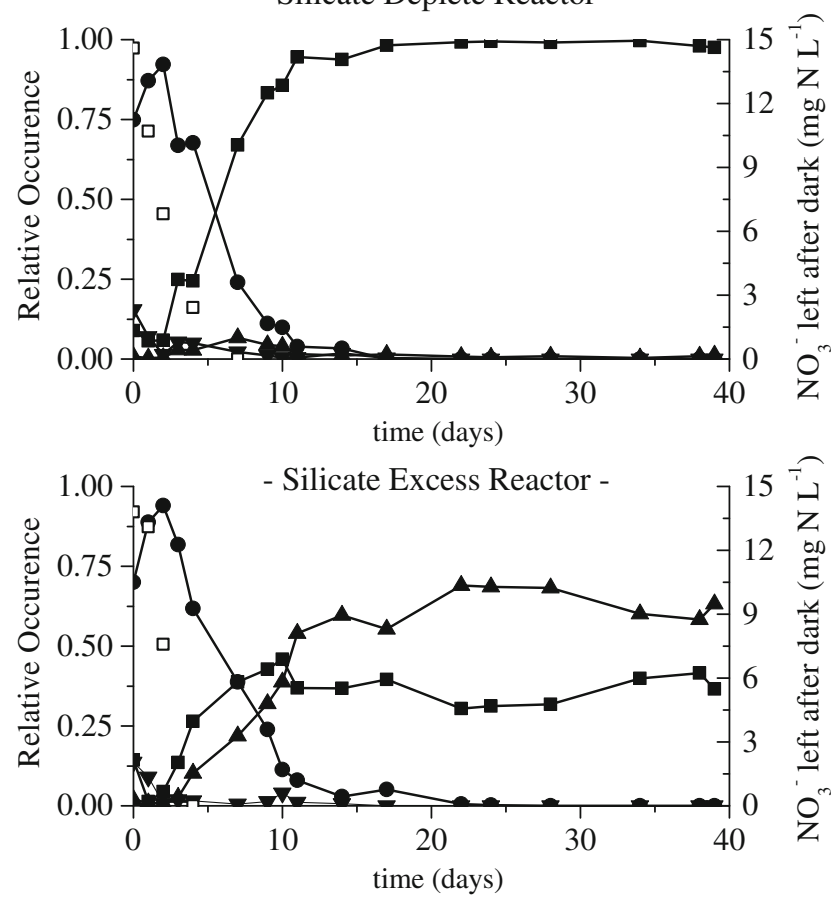

$\longrightarrow$ Chlamydomonas sp. $\longrightarrow$ Chlorella sp.
$\longrightarrow$ Nitzschia sp. $\longrightarrow$ Other species
$\square \quad \mathrm{NO}_{3}$ left after dark period

Fig. 2 Community structure (black lines, left y-axis) and nitrate left over after the dark phase (black open squares, right y-axis) in time for the silicate-depleted (top) and silicate-excess (bottom) reactors

\section{Storage compound productivity in the cycle}

The second aim of this study concerned the functional characteristics of both systems. In both reactors, large amounts of glucose polymers were produced, increasing from $17 \pm 4$ to 53 $\pm 5 \%$ and from $14 \pm 4$ to $43 \pm 4 \%$ on an organic matter basis during the light period for the silicate-depleted and silicateexcess reactors, respectively (Fig. 3). Diatoms are known to produce chrysolaminarin, a $\beta$-1,3-D-glucan, under nitrogen limitation (Granum and Myklestad 2001). Green algae produce starch under nitrogen-limited conditions (Markou et al. 2012). Both of these storage compounds will be measured as glucose monomers using our analytical methods. Lipid levels showed the same trends but were always significantly lower. The lipid fraction increased from $6 \pm 1$ to $7 \pm 2 \%$ and from $8 \pm 2$ to $10 \pm 2 \%$ on an organic matter basis during the light period for the silicate-depleted and silicate-excess reactors, respectively (data not shown). Comparing productivity values with literature values is difficult in the microalgae field. Studies differ in light input, reactor design, reactor operation, type of limitation, and other operational parameters. For pure cultures,
Glucose Polymer Content
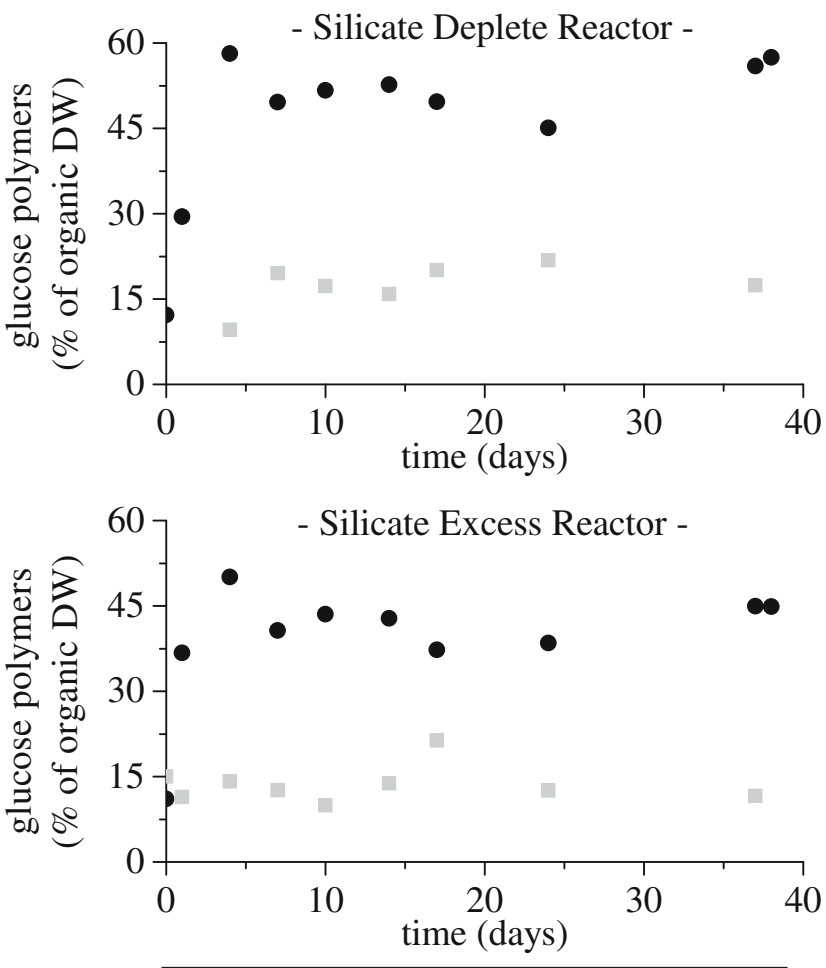

start light period • end light period

Fig. 3 Fraction of glucose polymers on organic dry weight basis at the start (gray squares) and at the end (black circles) of the light period in time for the silicate-depleted (top) and silicate-excess (bottom) reactors

glucose content values ranging from 41 to $62.1 \%$ of total dry solids are reported (Dragone et al. 2011; Pirt and Pirt 1977; Brányiková et al. 2011). The values obtained for our enrichment cultures are in the same range but are reported on an organic matter basis. Due to their siliceous cell wall, the ash content of diatoms accounts for up to $50 \%$ of the total dry solids. Comparing productivity between algae classes on a total dry solid basis should therefore be done with caution (Hildebrand et al. 2012).

\section{Stability}

From day 10 onward, storage compound production and the microalgal population were stable in both reactors for the remaining 27 days. With around $60 \%$ of the reactor volume harvested every day, these 27 days correspond to $30+$ generations of microalgae. Gas and liquid flows leaving and entering the reactors were not sterilized, and the reactors were manually cleaned, opening the reactors fully, every 3-4 days. Despite these disturbances, the systems were very stable both in terms of functional performance and microbial community structure, emphasizing the robustness of the approach used. 


\section{Conclusion}

In the work presented here, we show that uncoupling of carbon fixation in the light and nitrogen uptake in the dark under silicate-excess conditions enriched a diatom-dominated, glucose-polymer-producing microalgae community. In the absence of silicate, a green-algae-dominated community was obtained. Both communities showed the same characteristic of producing high amounts of storage compounds in the light period and stable community structure over time. These results indicate that the proposed method will enrich in any environment a storage compound-producing algae which thrives in this specific environment. As a consequence, it allows stable storage compound production in open, and therefore cheap, cultivation systems.

Acknowledgments This research was funded by the Dutch Foundation for Technical Sciences (STW) as project 11610 in the Waste 2 Resource (W2R) program. The authors are grateful to Ben Abbas and Mitchell Geleijnse for the PCR-DGGE work.

Conflict of interest The authors declare that there is no conflict of interest.

Open Access This article is distributed under the terms of the Creative Commons Attribution 4.0 International License (http:// creativecommons.org/licenses/by/4.0/), which permits unrestricted use, distribution, and reproduction in any medium, provided you give appropriate credit to the original author(s) and the source, provide a link to the Creative Commons license, and indicate if changes were made.

\section{References}

Brányiková I, Maršálková B, Doucha J, Brányik T, Bišová K, Zachleder V, Vítová M (2011) Microalgae — novel highly efficient starch producers. Biotechol Bioeng 108:766-776

Dragone G, Fernandes BD, Abreu AP, Vicente AA, Teixeira JA (2011) Nutrient limitation as a strategy for increasing starch accumulation in microalgae. Appl Energy 88:3331-3335

Egge JK, Aksnes DL (1992) Silicate as regulating nutrient in phytoplankton competition. Mar Ecol Prog Ser 83:281-289
Granum E, Myklestad SM (2001) Mobilization of $\beta$-1,3-glucan and biosynthesis of amino acids induced by $\mathrm{NH}_{4}^{+}$addition to N-limited cells of the marine diatom Skeletonema costatum (Bacillariophyceae). J Phycol 5:772-782

Hildebrand M, Davis AK, Smith SR, Traller JC, Abbriano R (2012) The place of diatoms in the biofuels industry. Biofuels 3:221-240

$\mathrm{Hu}$ Q, Sommerfeld M, Jarvis E, Ghirardi M, Posewitz M, Seibert M, Darzins A (2008) Microalgal triacylglycerols as feedstocks for biofuel production: perspectives and advances. Plant J 54:621-639

Kamp A, de Beer D, Nitsch JL, Lavik G, Stief P (2011) Diatoms respire nitrate to survive dark and anoxic conditions. Proc Natl Acad Sci U S A 108:5649-5654

Kazamia E, Aldridge DC, Smith AG (2012) Synthetic ecology - a way forward for sustainable algal biofuel production? J Biotechnol 1: $163-169$

Litchman E (2007) Resource competition and the ecological success of phytoplankton. In: Falkowski, Knoll AH (eds) Evolution of primary producers in the sea. Elsevier, Amsterdam, pp 351-375

Markou G, Angelidaki I, Georgakakis D (2012) Microalgal carbohydrates: an overview of the factors influencing carbohydrates production, and of main bioconversion technologies for production of biofuels. Appl Microbiol Biotechnol 96:631-645

McBride RC, Lopez S, Meenach C, Burnett M, Lee PA, Nohilly F, Behnke C (2014) Contamination management in low cost open algae ponds for biofuels production. Ind Biotechnol 10:221-227

Mooij PR, Stouten GR, Tamis J, van Loosdrecht MCM, Kleerebezem R (2013) Survival of the fattest. Energy Environ Sci 6:3404-3406

Mooij PR, de Graaff DR, van Loosdrecht MCM, Kleerebezem R (2014) Starch productivity in cyclically operated photobioreactors with marine microalgae - effect of ammonium addition regime and volume exchange ratio. J Appl Phycol 27:1-6

Mooij PR, Stouten GR, van Loosdrecht MCM, Kleerebezem R (2015) Ecology-based selective environments as solution to contamination in microalgal cultivation. Curr Opin Biotechnol 33:46-51

Pirt MW, Pirt SJ (1977) Photosynthetic production of biomass and starch by Chlorella in chemostat culture. J Chem Technol Biotechnol 27: 643-650

Shurin JB, Abbott RL, Deal MS, Kwan GT, Litchman E, McBride RC, Mandal S, Smith VH (2013) Industrial-strength ecology: trade-offs and opportunities in algal biofuel production. Ecol Lett 16:13931404

Sommer U (1985) Comparison between steady state and non-steady state competition: experiments with natural phytoplankton. Limnol Oceanogr 30:335-346

Werner D (1977) The biology of diatoms. Blackwell Scientific Publishing, Oxford

Wijffels RH, Barbosa MJ (2010) An outlook on microalgal biofuels. Science 329:796-799 